\title{
Crosstalk between monocytes and renal mesangial cells via interaction of metalloproteinases and fractalkine in diabetic nephropathy
}

\author{
YANPING WANG ${ }^{1}$, QIONG WEI $^{1}$, QIANG LIU ${ }^{1}$, ZHENG LI $^{1}$, LI ZHOU $^{1}$, \\ FANG ZOU ${ }^{1,2}$, YANG YUAN ${ }^{1}$ and ZILIN SUN ${ }^{1}$ \\ ${ }^{1}$ Department of Endocrinology, Zhongda Hospital, Institute of Diabetes, Medical School, \\ Southeast University, Nanjing, Jiangsu 210009; ${ }^{2}$ Department of Endocrinology, \\ The Second Affiliated Hospital of Nanchang University, Nanchang, Jiangxi 330006, P.R. China
}

Received March 29, 2013; Accepted September 19, 2013

DOI: $10.3892 / \mathrm{mmr} .2013 .1703$

\begin{abstract}
An increasing number of studies suggest that the activation of innate immunity with the development of a chronic low-grade inflammatory response is a factor in the pathogenesis of diabetic nephropathy (DN). Advanced glycation end products (AGEs), chemokines and matrix metalloproteinases (MMPs) are known to be important in inflammatory reactions in DN. In the present study, the inter-regulation of MMP2 and fractalkine was observed between monocytes (U937) and human renal mesangial cells (HRMCs) and its potential pathophysiological role in DN. The expression of fractalkine and MMP2 was analyzed by RT-PCR, western blot analysis and enzyme-linked immunosorbent assay. The chemotaxis and adhesiveness of HRMCs to U937 cells was detected with a transwell system, co-culture and fluorescent staining, respectively. The results showed a decreased expression of MMP2 and an increased expression of fractalkine by AGEs in HRMCs. Fractalkine downregulated the mRNA expression and activity of MMP2, and the reduced MMP2 activity was reversed with an anti-fractalkine antibody. Conversely, MMP2 upregulated fractalkine mRNA and protein expression in HRMCs, which led to an increase in chemotaxis and a decrease in monocytic adhesion to HRMCs. In conclusion, these observations suggest a crosstalk between monocytes and HRMCs via the interaction of MMP2 and fractalkine, which may represent a therapeutic target to impede the inflammatory process associated with DN.
\end{abstract}

Correspondence to: Professor Zilin Sun, Department of Endocrinology, Zhongda Hospital, Institute of Diabetes, Medical School, Southeast University, No. 87 Dingjiaqiao, Nanjing, Jiangsu 210009, P.R. China

E-mail: sunzilin1963@126.com

Key words: inflammatory, co-culture, therapeutic target

\section{Introduction}

Diabetes mellitus (DM) and its complications have become one of the most important health problems worldwide. Diabetic nephropathy (DN) is the predominant cause of end-stage renal disease that requires renal transplantation $(1,2)$. Formation and accumulation of advanced glycation end products (AGEs) is closely linked with the aging process and is accelerated in DM. The pathogenic role of AGEs in vascular diabetic complications is widely recognized. AGEs and RAGE (the receptor for AGEs) elicit inflammatory reactions leading to vascular damage (2-4). Oxidative stress and inflammatory molecules including inflammatory cytokines, chemokines and adhesion molecules are intimately involved in the development and progression of $\mathrm{DN}(5,6)$. There is an increasing number of studies suggesting that kidney macrophage recruitment is related to hyperglycemia and the accumulation of AGEs, and that macrophage-mediated injury is fundamental in the onset of DN (7-9).

Chemokines that are detected in the circulation and kidney of humans and animals are generally increased following the onset and further progress of DM, which is frequently accompanied by the promotion of macrophage recruitment in kidney (10). Fractalkine is one of the two chemokines which is expressed in soluble (s-fractalkine) and transmembrane/mucin hybrid forms, which therefore combines chemoattractant and adhesiveness functions (11). The fractalkine/CX3CR1 (receptor of fractalkine) axis has been implicated in the pathogenesis of atherosclerosis, DM and streptozotocin-induced DN along the glomerular capillary lumen and peritubular capillaries (12-15).

Matrix metalloproteinase 2 (MMP2) belongs to a subgroup of MMPs termed gelatinases and it has been implicated in the pathological processes that contribute to fibrotic diseases, tumor progression and inflammation (16-18). It predominantly contributes to the breakdown and turnover of extracellular matrix (ECM), which is manifested in mesangial expansion, glomerulosclerosis and tubulointerstitial fibrosis in the kidney (19-21). MMPs cleave proteins, solubilize pericellular matrix and shed cellular ectodomains (22). 
The present study aimed to investigate the function of fractalkine and MMP2 as well as the interaction between the two proteins using a human renal mesangial cell (HRMC)-monocyte co-culture system. It was demonstrated that AGEs upregulated fractalkine and downregulated MMP2 in the monocytes-HRMC co-culture system. Thus, it was hypothesized that there is crosstalk between monocytes and HRMCs via the interaction of MMP2 and fractalkine, which may be important in the AGE-mediated development of DN.

\section{Materials and methods}

Materials. All experiments were conducted in serum-free RPMI-1640 medium containing $0.2 \%$ bovine serum albumin (BSA), $2 \mathrm{mmol} / 1$ glutamine, $100 \mathrm{U} / \mathrm{ml}$ penicillin and $100 \mu \mathrm{g} / \mathrm{ml}$ streptomycin. All reagents for cell culture were obtained from Sigma-Aldrich (St. Louis, MO, USA). Recombinant MMP2 was obtained from PeproTech (Rocky Hill, NJ, USA; lot no. 057106). Anti-fractalkine polyclonal antibody was obtained from R\&D Systems (Minneapolis, MN, USA; lot no. EKC10).

Preparation of AGEs. BSA (50 g/l) was incubated with $0.5 \mathrm{mmol} / 1 \mathrm{D}$-glucose in $0.2 \mathrm{mmol} / 1$ phosphate-buffered saline (PBS, pH 7.4) at $37^{\circ} \mathrm{C}$ for 90 days. The control sample of BSA was also incubated under the same conditions but without glucose. Following incubation, AGE-BSA was purified by Sephadex G-200 (Sigma; Lot 271233). The Bradford method was used for the quantification of proteins $(23,24)$.

Cell culture. An established stable HRMC (donated by Dr XZ Ruan, University College London, London, UK) was cultured in RPMI-1640 medium with $10 \%$ fetal calf serum (FCS), $2 \mathrm{mmol} / \mathrm{l}$ glutamine, $100 \mathrm{U} / \mathrm{ml}$ penicillin and $100 \mu \mathrm{g} / \mathrm{ml}$ streptomycin.

The U937 monocyte-like cell line cells (obtained from Professor BC Liu, Southeast University, Nanjing, Jiangsu, China) were grown in suspension in the RPMI-1640 culture medium containing 5\% FCS and were split by 1:5, twice per week. The study was approved by the Ethics Committee of Southeast University.

$R T-P C R$. Total RNA was isolated from cells using TRIzol reagent [from the RevertAid ${ }^{\mathrm{TM}}$ First Strand cDNA synthesis kit (Invitrogen, Carlsbad, CA, USA; Lot 1382739)]. An aliquot of $2 \mu \mathrm{g}$ total RNA from each sample was reverse transcribed to cDNA using the reverse transcript system (RevertAid First Strand cDNA synthesis kit) according to the manufacturer's instructions. The mRNA levels of the analyzed molecules were normalized to $\beta$-actin or glyceraldehyde 3 -phosphate dehydrogenase (GAPDH) mRNA levels. The following primers were used for the amplification of mRNA: Forward: 5'-AGCCACAGGCGAAAGCAGTA-3' and reverse: 5'-TTCAGACGGAGCATTCTCCT-3' for fractalkine; and forward: 5'-ACAAAGAGTTGGCAGTGCAAT-3' and reverse: 5'-GGGTCACATCGCTCCAGACTTGG-3' for MMP2. Amplification of cDNA was conducted with the following primers: Forward: 5'-CGCCGCGCTCGTCGTCGACA-3' and reverse: 5'-GTCACGCACGATTTCCCGCT-3' for $\beta$-actin; and forward: 5'-GGAGTCAACGGATTTGGT-3' and reverse: 5'-GTGATGGGATTTCCATTGAT-3' for GAPDH. The sizes of the expected PCR products for the fractalkine, MMP2, $\beta$-actin and GAPDH primers were 340, 330, 619 and 206 bp, respectively.

Western blot analysis. The cell lysates were prepared with lysis buffer, radio immunoprecipitation assay (RIPA) and mammalian protease inhibitor mixture (Shenerg Biocolor, Shanghai, China). Whole cell lysates were centrifuged at $15,000 \mathrm{x} \mathrm{g}$ for $20 \mathrm{~min}$ at $4^{\circ} \mathrm{C}$ to remove the insoluble material. The protein concentrations were determined by the Bradford method using a BCA Protein Micro Assay kit (Shenerg Biocolor). The cell lysates were loaded onto sodium dodecyl sulfate-polyacrylamide gels and transferred onto polyvinylidene difluoride membranes. The membranes were blocked and incubated with the primary anti-fractalkine antibody (dilution, 1:400; R\&D Systems, Minneapolis, MN, USA) or anti- $\beta$-actin antibody (dilution, 1:2,000; R\&D Systems) in PBS-Tween, followed by incubation with horseradish peroxidase-conjugated secondary antibodies. The proteins were visualized with 3,3'-diaminobenzidine tetrahydrochloride dihydrate (DAB; Sigma-Aldrich). The membrane was scanned and quantitated using a GelDoc-It TS Imaging System (UVP, Upland, CA, USA). Results were expressed in arbitrary units as folds of control.

Gelatin zymography assay. Conditioned medium collected from cultured HRMCs was electrophoresed under non-reducing conditions on $10 \%$ polyacrylamide gels containing $1 \mathrm{mg} / \mathrm{ml}$ gelatin as the substrate. Following electrophoresis, the gels were re-natured in $2.5 \%$ Triton $\mathrm{X}-100(2 \times 30 \mathrm{~min})$ and then incubated $\left(18 \mathrm{~h}, 37^{\circ} \mathrm{C}\right)$ in a buffer containing $50 \mathrm{mM}$ Tris- $\mathrm{HCl}$, $\mathrm{pH} 7.4,5 \mathrm{mM} \mathrm{CaCl}_{2}$ and $150 \mathrm{mM} \mathrm{NaCl}$. Subsequent to this, the gels were stained with $0.25 \%$ Coomassie brilliant blue R-250 and de-stained with $10 \%$ acetic acid and $40 \%$ methanol. The white bands against the blue background indicated the presence of gelatinolytic activity. Image acquisition was conducted with Image Master VDS and LisCap software (Amersham Pharmacia Biotech, Amersham, UK). Computerized densitometry was used to analyze the relative enzymatic activity.

Monocyte chemotaxis assay. HRMCs were harvested and washed in serum-free RPMI-1640. Cells were then incubated with MMP2 for $6 \mathrm{~h}$ and washed three times. A transwell system was used in the medium with U937 cells inside and incubated $\left(3 \mathrm{~h}, 37^{\circ} \mathrm{C}\right)$. Following staining with hematoxylin for $10 \mathrm{~min}$, cells with purple staining were counted.

Monocyte adhesive assay. HRMCs were harvested and washed in serum-free RPMI-1640. Cells were then incubated with MMP2 for $6 \mathrm{~h}$ and washed with PBS. U937 cells were stained with Calcein-AM (30 min, $\left.37^{\circ} \mathrm{C}\right)$ and co-cultured with HRMCs $\left(3 \mathrm{~h}, 37^{\circ} \mathrm{C}\right)$. Subsequent to washing, cells exhibiting blue staining were counted.

Data analysis. Data are expressed as the mean \pm SD. In all experiments, groups of data were evaluated for significance using one-way analysis of variance or a student-Newman-Keuls test. $\mathrm{P}<0.05$ was considered to indicate a statistically significant difference. SPSS 13.0 software (SPSS, Inc., Chicago, IL, USA) was used to determine significance. 
A
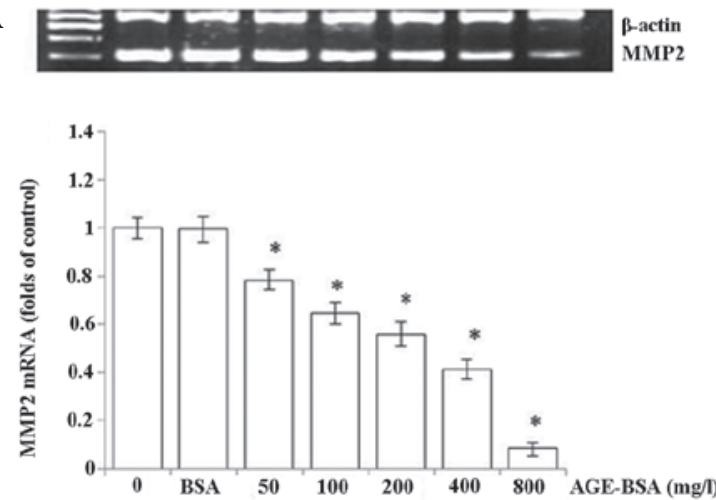

C
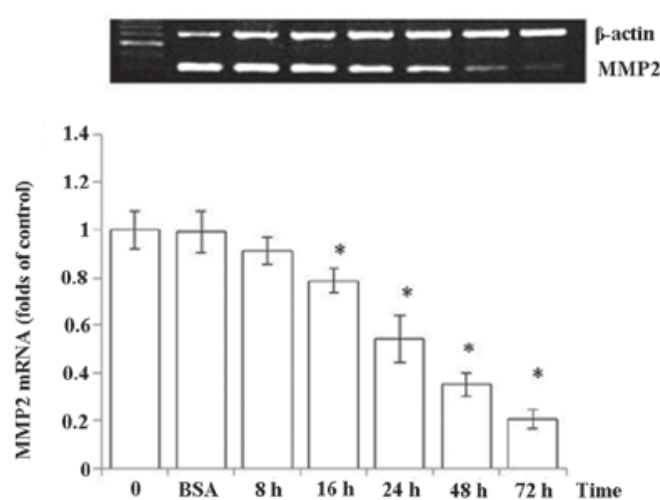

B
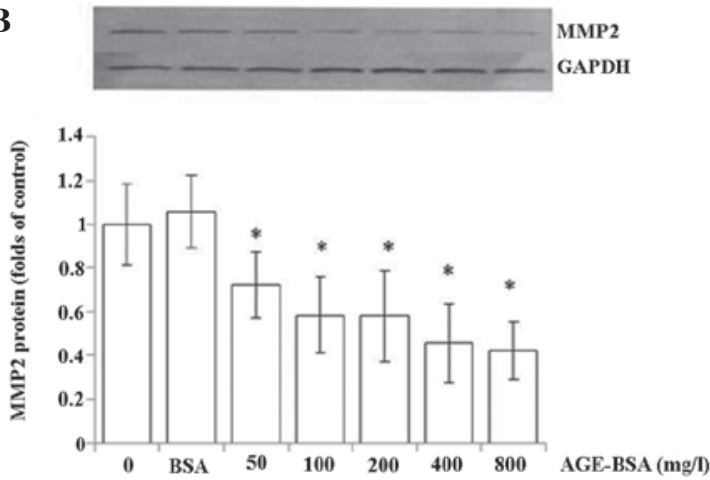

D
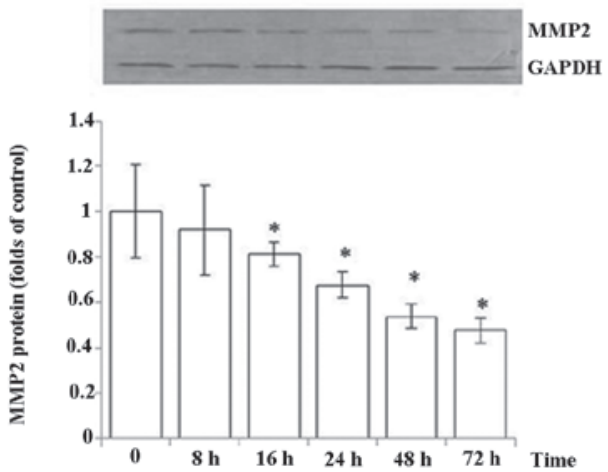

Figure 1. Effect of advanced glycation end products (AGEs) on matrix metalloproteinase 2 (MMP2) expression. (A and B) Human renal mesangial cells (HRMCs) were cultured with various concentrations of AGE-bovine serum albumin (BSA) for $24 \mathrm{~h}$. (C and D) HRMCs were cultured with $200 \mathrm{mg} / \mathrm{ml}$ AGE-BSA for various time periods. (A and C) Transcript levels of MMP2 were quantitated using RT-PCR. (B and D) Protein levels of MMP2 were quantified using western blot analysis. Data are represented as the mean $\pm \mathrm{SD}, \mathrm{n}=8 .{ }^{*} \mathrm{P}<0.05$, compared with control.

\section{Results}

Effects of AGEs on MMP2 in HRMCs. The expression of MMP2 in HRMCs was assessed following incubation with various concentrations of $\operatorname{AGEs}(0,50,100,200,400$ and $800 \mathrm{mg} / \mathrm{ml}$ ) and BSA, by mRNA and protein analysis. As shown in Fig. 1A and B, MMP2 mRNA and protein levels as assessed in HRMCs decreased dose dependently. There was also a time-dependent reduction of MMP2 mRNA and protein expression while treated with $200 \mathrm{mg} / \mathrm{ml}$ AGEs (0, 8, 16, 24, 48 and $72 \mathrm{~h}$ ) and BSA (Fig. 1C and D). There appeared to be a greater reduction in the mRNA than the protein level, suggesting potential post-transcriptional regulation of MMP2 in response to AGE-BSA treatment.

Effects of AGEs on fractalkine in HRMCs. In contrast to the significant reduction of MMP2 expression in response to AGE-BSA in HRMCs, a marked increase of mRNA and protein levels of fractalkine in HRMCs was readily detected in an AGE-BSA concentration and time-dependent manner. The initial concentration that was sufficient to induce this regulation was $50 \mathrm{mg} / \mathrm{l}$, consistent with the observation in the MMP2 experiment (Fig. 2).

Regulation of MMP2 in U937 by fractalkine. The present study investigated how MMP2 expression in U937 cells is regulated by fractalkine in two experiments. U937 cells were treated with increasing concentrations of fractalkine and the levels of MMP2 were measured. A significant reduction of MMP2 mRNA and protein was observed upon treatment with fractalkine in U937 cells. A U937 and HRMC co-culture experiment was also conducted to investigate the same question. Co-culture of U937 cells with HRMCs led to a significant reduction of the MMP2 mRNA level in U937 cells (Fig. 3A). This regulation was blocked when a monoclonal antibody against fractalkine was added to the culture medium (Fig. 3C). Consistent with the observation at the mRNA level, the measurement of the MMP2 activity using a gelatin zymography assay also demonstrated that the reduced MMP2 activity was reversed with the administration of the fractalkine antibody (Fig. 3B and D). Collectively, these studies indicated that fractalkine regulates MMP2 expression in U937 cells.

Regulation of fractalkine in HRMCs by MMP2. To determine whether MMP2 regulates fractalkine expression in HRMCs, HRMCs were treated with increasing concentrations of MMP2 $(0,0.5,1,2,3,4$ and $5 \mathrm{ng} / \mathrm{ml})$. As shown in Fig. 4, a marked increase of fractalkine was observed in a dose-dependent manner.

Effects of fractalkine in HRMCs treated with MMP2. Fractalkine exists in soluble and membrane bound forms that exhibit differential involvement in chemotaxis and cell adhesion. Soluble fractalkine is critical in mediating the chemotaxis effect of monocytes, while the membrane bound 
A
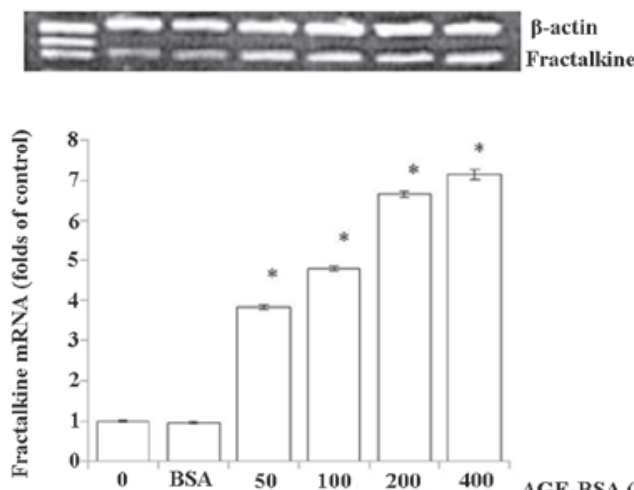

C
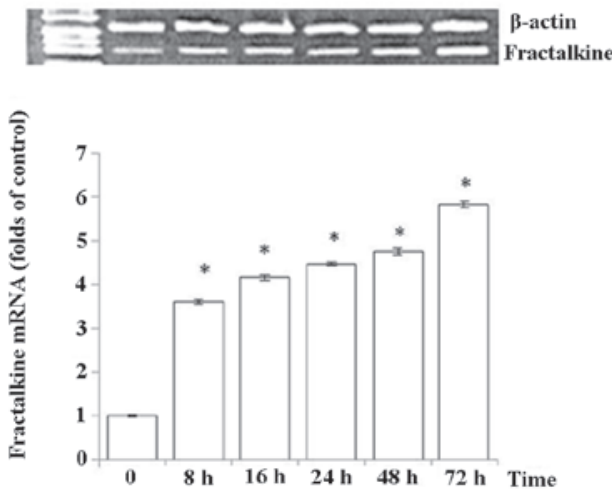

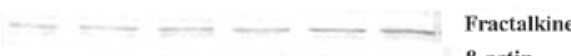

B-actin

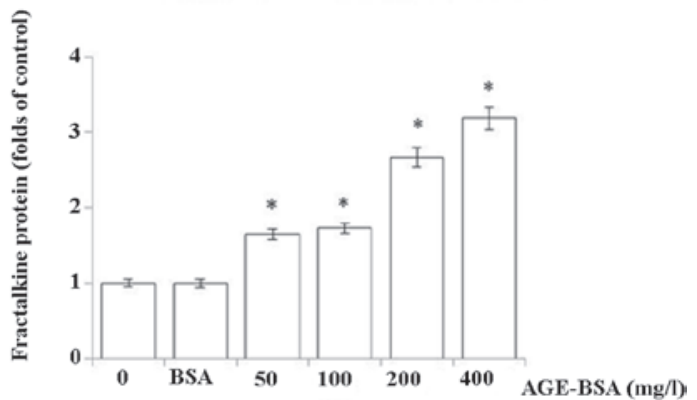

D
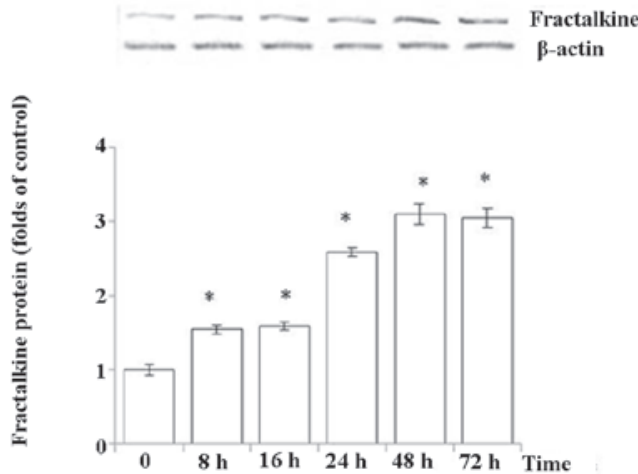

Figure 2. Effect of advanced glycation end products (AGEs) on fractalkine expression. (A and B) Human renal mesangial cells (HRMCs) were cultured with various concentrations of AGE-bovine serum albumin (BSA) for $24 \mathrm{~h}$. (C and D) HRMCs were cultured with 200 mg/ml AGE-BSA for various times. (A and C) Transcript levels of fractalkine were analyzed and quantified using RT-PCR. (B and D) Protein levels of fractalkine were analyzed and quantified using western blot analysis. Data are represented as the mean $\pm \mathrm{SD}, \mathrm{n}=8$. ${ }^{*} \mathrm{P}<0.05$, compared with control.

A
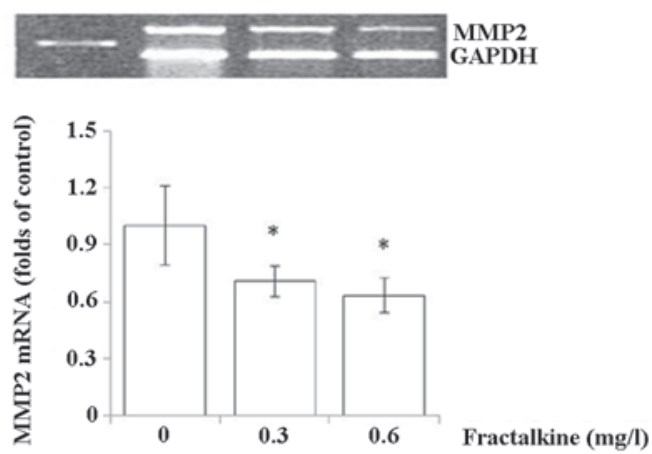

C
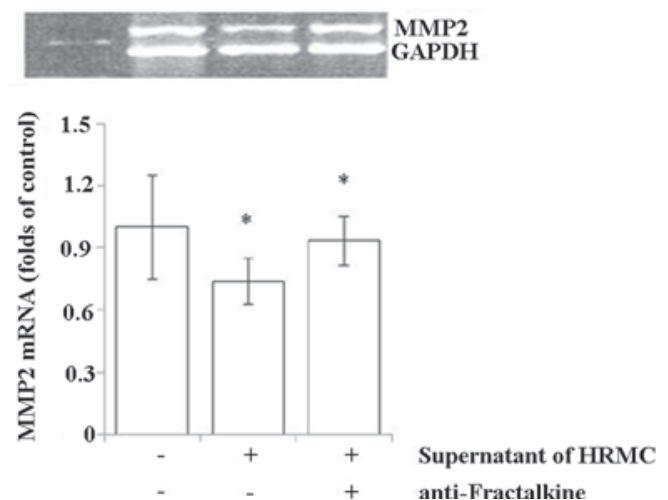

B
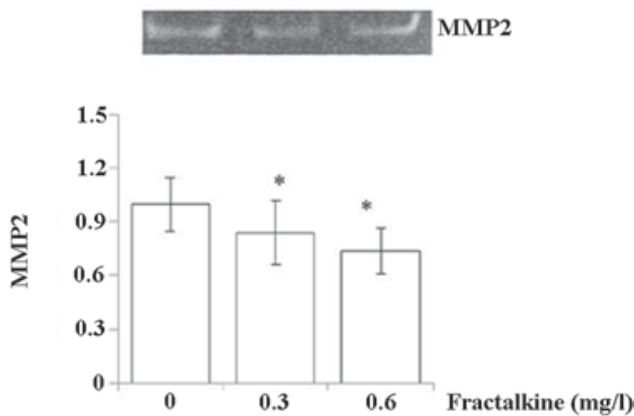

D
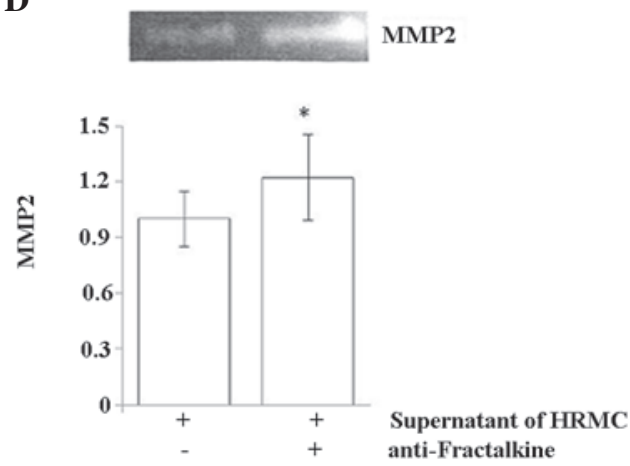

Figure 3. Regulation of matrix metalloproteinase 2 (MMP2) in U937 cells by fractalkine. (A and B) mRNA and protein regulation of MMP2 by fractalkine in U937 cells. U937 cells were cultured and treated with different concentrations of fractalkine and the MMP2 mRNA and protein levels were analyzed as described in the Materials and methods. (C and D) mRNA level and the activity of MMP2 is mediated by fractalkine. A monoclonal antibody was used to block the function of fractalkine and the mRNA and the MMP2 activity were analyzed as described in the Materials and methods. Data are represented as the mean $\pm \mathrm{SD}, \mathrm{n}=8$. $\mathrm{P}<0.05$, compared with control. 
A
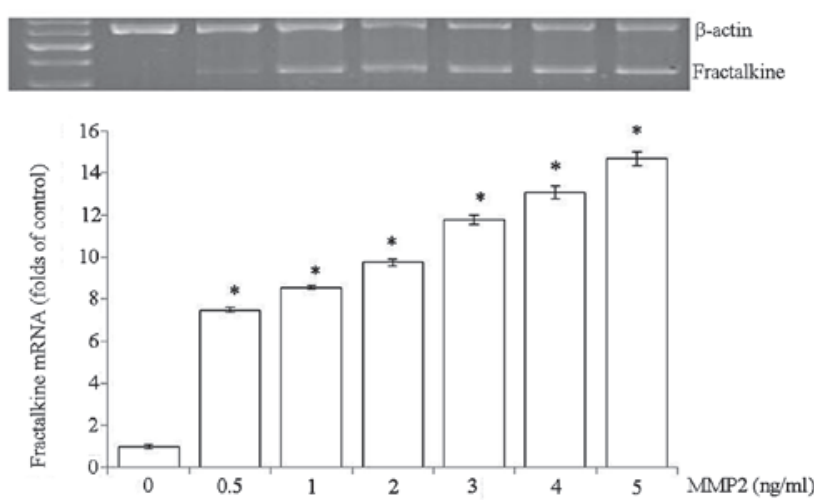
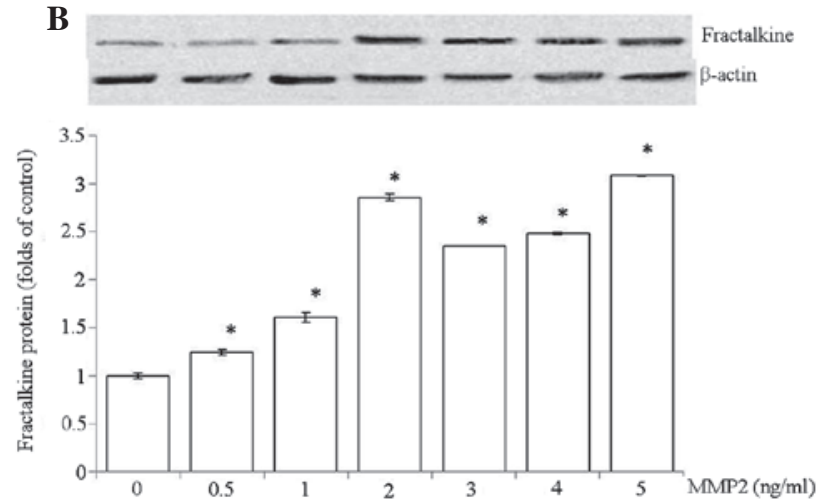

Figure 4. Effect of matrix metalloproteinase 2 (MMP2) on fractalkine mRNA and protein expression. Human renal mesangial cells (HRMCs) were cultured with MMP2 for $24 \mathrm{~h}$. (A) Transcript levels of fractalkine were quantified using RT-PCR. (B) Protein levels of fractalkine were measured and quantified using western blot analysis. Data are represented as the mean $\pm \mathrm{SD}, \mathrm{n}=8$. ${ }^{*} \mathrm{P}<0.05$, compared with control.

A

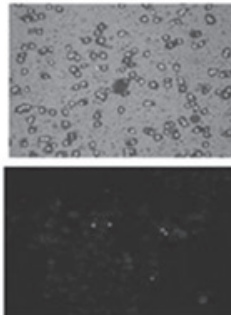

0

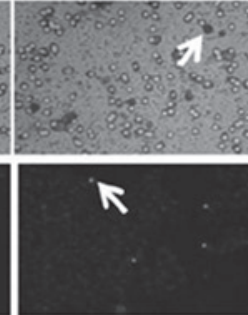

0.625
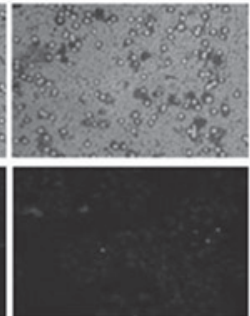

1.25

B

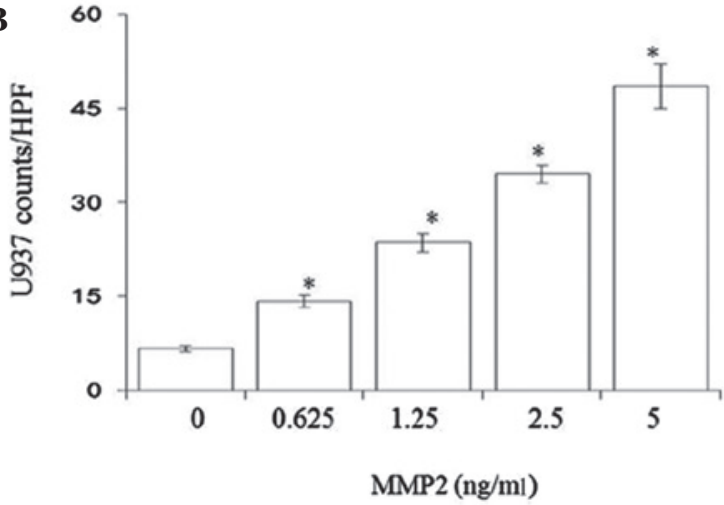

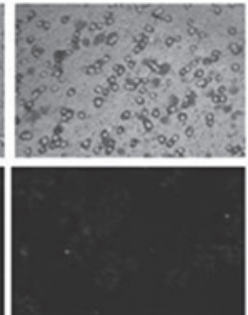

2.5

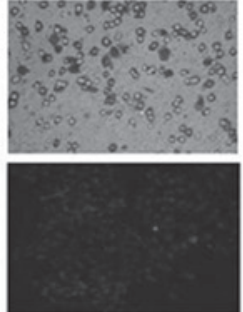

Chemotaxis

Adhesiveness

$\operatorname{MMP2}(\mathrm{ng} / \mathrm{ml})$

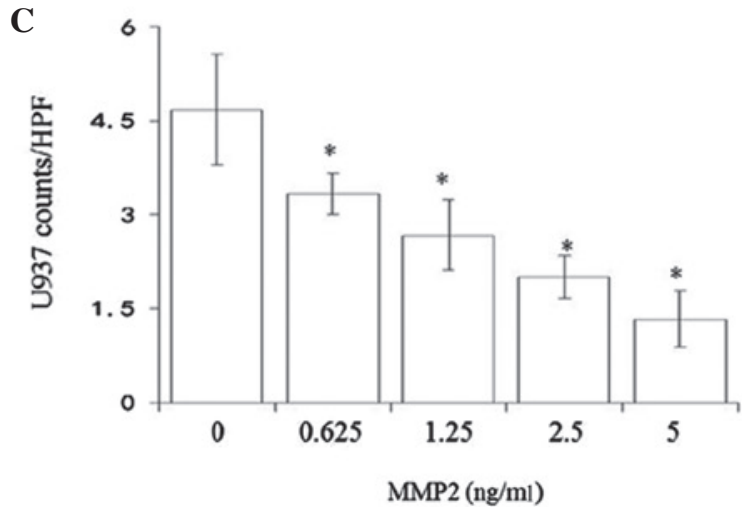

Figure 5. Matrix metalloproteinase 2 (MMP2) regulates monocyte transmigration and adhesion in human renal mesangial cell (HRMC)/U937 co-culture. HRMCs were incubated with MMP2 for $24 \mathrm{~h}$. (A and B) U937 cell transmigration and (A and C) adhesion to HRMCs was detected and quantified using a transwell system as described in the Materials and methods. Arrows indicate U937 cells. Data are represented as the mean $\pm \mathrm{SD}, \mathrm{n}=8$. $\mathrm{P}<0.05$, compared with control.

form primarily regulates cell adhesion. The functional consequence of fractalkine regulation in HRMCs was thus investigated in a transwell system, in which HRMCs and U937 cells were co-cultured in different compartments and U937 cell transmigration and adhesion were analyzed as described in the Materials and methods. The number of U937 cells that transmigrated to HRMCs treated with MMP2 increased dose dependently $(0,0.625,1.25,2.5$ and $5 \mathrm{ng} / \mathrm{ml})$ compared with the control, but the number that adhered decreased (Fig. 5). These results suggested that MMP2 may largely produce the soluble form of fractalkine that primarily mediates cell transmigration, instead of the membrane bound form that mediates cell adhesion.

\section{Discussion}

Chronic hyperglycemia, a necessary prerequisite for the development of DN leads to the formation of long-lived, non-enzymatically glycated proteins referred to as AGEs (2). As a consequence of increased substrate (glucose) availability, AGEs accumulate at an accelerated rate in diabetic patients, and they have been postulated to be essential in the pathogenesis of the microvascular complications of DM. In the present study, it was demonstrated that MMP2 expression was diminished by AGE treatment, which may lead to the accumulation of ECM. In addition, fractalkine mRNA and protein levels in HRMCs were demonstrated to be significantly upregulated by AGEs 
in a dose-dependent manner. It is known that s-fractalkine exhibits chemoattractant activity for $\mathrm{T}$ cells and monocytes, whereas cell surface-bound fractalkine promotes strong adhesion of those leukocytes via its receptor, CX3CR1. The results demonstrating that AGEs regulate MMP2 and fractalkine expression, suggest the potential involvement of AGEs in DN through macrophage recruitment and ECM accumulation in the kidney.

Our results are consistent with previous studies that have demonstrated the interaction between chemokine and MMP systems in multiple physiological and pathological processes (25-27). Thus, the interaction between chemokine and MMP systems in DN was investigated via the monocyte-HRMC co-culture system. It was demonstrated that fractalkine downregulated the mRNA expression and activity of MMP2, which was involved in ECM degradation. Abnormal ECM deposition is the hallmark of diabetic nephropathy and ECM is essential for monocyte extravasation and migration into the tissues (28). Furthermore, numerous studies have suggested that chemokines are key in the regulation of MMPs during transmigration (29-30). Vitale et al (27) showed that s-fractalkine inhibits the activity of MMP2 secreted by monocytes. The observation that s-fractalkine limits monocyte migration in response to MCP-1 suggests a critical involvement of s-fractalkine in the control of the inflammatory process (27). While the mechanism through which MMP2 expression is inhibited by fractalkine remains to be elucidated, the results of the present study along with others, suggested the involvement of fractalkine in facilitating monocyte and $\mathrm{T}$ cell transmigration as a chemokine, by suppressing MMP2 secretion from monocytes.

It was also observed that MMP2 upregulated fractalkine at the mRNA and protein levels. Further, in the co-culture experiment, it was demonstrated that monocytic cell transmigration was increased while cell adhesion was reduced. Fractalkine is initially synthesized as an intracellular precursor that undergoes glycosylation and is transported to the cell surface as a $100-\mathrm{kDa}$ glycoprotein. It then presents itself in two forms, a membrane-anchored form which acts as an adhesion molecule $(100 \mathrm{kDa})$ or a soluble chemoattractant extracellular form (ADAM17; $85 \mathrm{kDa}$ ) consisting of its mucin stalk and chemokine domain that is shed from the cell membrane by phorbol 12-myristate 13 -acetate or tumor necrosis factor-converting enzyme. ADAMs are type I transmembrane proteins that contain a disintegrin-like and metalloproteinase-like domain $(31,32)$. It has been shown that the release of the CX3CL1 soluble form is closely associated with MMP2 activity (33-35). Dean and Overall (36) showed the release of the chemokine domain from the cell membrane by MMP2 cleavage specifically at amino acid 69 AAA $\uparrow$ TK. Furthermore, it was identified that an N-terminal tetrapeptide truncation of the chemokine domain that is deficient in chemotactic activity acted as a potent antagonist of CX3CR (37). Thus, it was hypothesized that the increased expression of fractalkine in the co-culture system existed predominantly in the soluble form as increased monocyte transmigration rather than cell adhesion was observed.

In conclusion, AGEs increased fractalkine and decreased MMP2 expression in HRMCs. Monocyte-HRMC co-culture studies demonstrated that fractalkine downregulated the
mRNA expression and activity of MMP2, and MMP2 increased the expression of fractalkine that primarily served as a chemoattractant. The results suggest a crosstalk between monocytes and HRMCs via the interaction of MMP2 and fractalkine, which may be involved in abnormal ECM deposition and monocyte migration into the tissues. It was shown that AGEs not only downregulate MMP2 directly, but also regulate MMP2 indirectly by upregulating fractalkine. In addition, MMP2 mediated the upregulation of AGEs to fractalkine. These results may improve our understanding of the inflammatory mechanisms of DN and suggest a crosstalk between monocytes and HRMCs via the interaction of MMP2 and fractalkine, which may represent a therapeutic target to impede the inflammatory process associated with DN.

\section{References}

1. Kaul K, Hodgkinson A, Tarr JM, Kohner EM and Chibber R: Is inflammation a common retinal-renal-nerve pathogenic link in diabetes? Curr Diabetes Rev 6: 294-303, 2010.

2. Busch M, Franke S, Rüster C and Wolf G: Advanced glycation end-products and the kidney. Eur J Clin Invest 40: 742-755, 2010.

3. Yamagishi S: Role of advanced glycation end products (AGEs) and receptor for AGEs (RAGE) in vascular damage in diabetes. Exp Gerontol 46: 217-224, 2011.

4. Navarro-González JF and Mora-Fernández C: Inflammatory pathways. Contrib Nephrol 170: 113-123, 2011.

5. Yamagishi $\mathrm{S}$ and Imaizumi T: Diabetic vascular complications: pathophysiology, biochemical basis and potential therapeutic strategy. Curr Pharm Des 11: 2279-2299, 2005.

6. van Dijk C and Berl T: Pathogenesis of diabetic nephropathy. Rev Endocr Metab Disord 5: 237-248, 2004.

7. Furuta T, Saito T, Ootaka T, Soma J, Obara K, Abe K and Yoshinaga K: The role of macrophages in diabetic glomerulosclerosis. Am J Kidney Dis 21: 480-485, 1993.

8. Nguyen D, Ping F, Mu W, Hill P, Atkins RC and Chadban SJ: Macrophage accumulation in human progressive diabetic nephropathy. Nephrology (Carlton) 11: 226-231, 2006.

9. Yonemoto S, Machiguchi T, Nomura K, Minakata T, Nanno M and Yoshida H: Correlations of tissue macrophages and cytoskeletal protein expression with renal fibrosis in patients with diabetes mellitus. Clin Exp Nephrol 10: 186-192, 2006.

10. Chow F, Ozols E, Nikolic-Paterson DJ, Atkins RC and Tesch GH: Macrophages in mouse type 2 diabetic nephropathy: correlation with diabetic state and progressive renal injury. Kidney Int 65: 116-128, 2004.

11. Braunersreuther V, Mach F and Steffens S: The specific role of chemokines in atherosclerosis. Thromb Haemost 97: 714-721, 2007.

12. Bazan JF, Bacon KB, Hardiman G, Wang W, Soo K, Rossi D, Greaves DR, Zlotnik A and Schall TJ: A new class of membrane-bound chemokine with a CX3C motif. Nature 385: 640-644, 1997.

13. Wong BW, Wong D and McManus BM: Characterization of fractalkine (CX3CL1) and CX3CR1 in human coronary arteries with native atherosclerosis, diabetes mellitus, and transplant vascular disease. Cardiovasc Pathol 11: 332-338, 2002.

14. Kikuchi Y, Ikee R, Hemmi N, Hyodo N, Saigusa T, Namikoshi T, Yamada M, Suzuki S and Miura S: Fractalkine and its receptor, CX3CR1, upregulation in streptozotocin-induced diabetic kidneys. Nephron Exp Nephrol 97: e17-e25, 2004.

15. Lesnik P, Haskell CA and Charo IF: Decreased atherosclerosis in $\mathrm{CX}_{3} \mathrm{CR}^{-/-}$mice reveals a role for fractalkine in atherogenesis. J Clin Invest 111: 333-340, 2003.

16. Visse R and Nagase H: Matrix metalloproteinases and tissue inhibitors of metalloproteinases: structure, function, and biochemistry. Circ Res 92: 827-839, 2003.

17. Corbel M, Belleguic C, Boichot E and Lagente V: Involvement of gelatinases (MMP-2 and MMP-9) in the development of airway inflammation and pulmonary fibrosis. Cell Biol Toxicol 18: 51-61, 2002.

18. John A and Tuszynski G: The role of matrix metalloproteinases in tumor angiogenesis and tumor metastasis. Pathol Oncol Res 7: $14-23,2001$. 
19. Brosius FC III: New insights into the mechanisms of fibrosis and sclerosis in diabetic nephropathy. Rev Endocr Metab Disord 9: 245-254, 2008.

20. Alsaad KO and Herzenberg AM: Distinguishing diabetic nephropathy from other causes of glomerulosclerosis: an update. J Clin Pathol 60: 18-26, 2007.

21. Mason RM and Wahab NA: Extracellular matrix metabolism in diabetic nephropathy. J Am Soc Nephrol 14: 1358-1373, 2003.

22. Nagase $\mathrm{H}$ and Woessner JF Jr: Matrix metalloproteinases. J Biol Chem 274: 21491-21494, 1999.

23. Sun Z, Liu N and Liu B: The preparation and application of antiserum against advanced glycated end products. Chin J Lab Med 5: 293-295, 1999 (In Chinese).

24. Zilin S, Naifeng L, Bicheng L and Jiping W: The determination of AGE-peptides by flow injection assay, a practical marker of diabetic nephropathy. Clin Chim Acta 313: 69-75, 2001.

25. Kenig S, Alonso MB, Mueller MM and Lah TT: Glioblastoma and endothelial cells cross-talk, mediated by SDF-1, enhances tumour invasion and endothelial proliferation by increasing expression of cathepsins B, S, and MMP-9. Cancer Lett 289. 53-61, 2010.

26. Tang $\mathrm{CH}$, Tan TW, Fu WM and Yang RS: Involvement of matrix metalloproteinase-9 in stromal cell-derived factor-1/CXCR4 pathway of lung cancer metastasis. Carcinogenesis 29: 35-43, 2008.

27. Vitale S, Schmid-Alliana A, Breuil V, Pomeranz M, Millet MA, Rossi B and Schmid-Antomarchi H: Soluble fractalkine prevents monocyte chemoattractant protein-1-induced monocyte migration via inhibition of stress-activated protein kinase $2 / \mathrm{p} 38$ and matrix metalloproteinase activities. J Immunol 172: 585-592, 2004.

28. Klier CM, Nelson EL, Cohen CD, Horuk R, Schlöndorff D and Nelson PJ: Chemokine-induced secretion of gelatinase $B$ in primary human monocytes. Biol Chem 382: 1405-1410, 2001.
29. Cross AK and Woodroofe MN: Chemokine modulation of matrix metalloproteinase and TIMP production in adult rat brain microglia and a human microglial cell line in vitro. Glia 28: 183-189, 1999.

30. Madri JA and Graesser D: Cell migration in the immune system: the evolving inter-related roles of adhesion molecules and proteinases. Dev Immunol 7: 103-116, 2000.

31. Garton KJ, Gough PJ, Blobel CP, Murphy G, Greaves DR, Dempsey PJ and Raines EW: Tumor necrosis factor-alpha-converting enzyme (ADAM17) mediates the cleavage and shedding of fractalkine (CX3CL1). J Biol Chem 276: 37993-38001, 2001.

32. Tsou CL, Haskell CA and Charo IF: Tumor necrosis factor-alpha-converting enzyme mediates the inducible cleavage of fractalkine. J Biol Chem 276: 44622-44626, 2001.

33. Théret N, Musso O, L'Helgoualc'h A and Clément B: Activation of matrix metalloproteinase-2 from hepatic stellate cells requires interactions with hepatocytes. Am J Pathol 150: 51-58, 1997.

34. Théret N, Lehti K, Musso O and Clément B: MMP2 activation by collagen I and concanavalin A in cultured human hepatic stellate cells. Hepatology 30: 462-468, 1999.

35. Bourd-Boittin K, Basset L, Bonnier D, L'Helgoualc'h A, Samson M and Théret N: CX3CL1/fractalkine shedding by human hepatic stellate cells: contribution to chronic inflammation in the liver. J Cell Mol Med 13: 1526-1535, 2009.

36. Dean RA and Overall CM: Proteomics discovery of metalloproteinase substrates in the cellular context by iTRAQ labeling reveals a diverse MMP-2 substrate degradome. Mol Cell Proteomics 6: 611-623, 2007

37. Inoue A, Hasegawa $H$, Kohno M, Ito MR, Terada M, Imai $T$, Yoshie O, Nose M and Fujita S: Antagonist of fractalkine (CX3CL1) delays the initiation and ameliorates the progression of lupus nephritis in MRL/lpr mice. Arthritis Rheum 52: 1522-1533, 2005. 